\title{
Agreed; but if...?
}

\author{
Stephen Hancocks OBE \\ Editor-in-Chief
}

The BDJ Upfront section includes editorials, letters, news, book reviews and interviews. Please direct your correspondence to the News Editor,

Kate Quinlan at BDJNews@nature.com. Press releases or articles may be edited, and should include a colour photograph if possible.

$\mathrm{T}$ he subject of ethics can often seem a dry and rather dull topic. We are, after all, practical people who like 'doing' things as distinct from spending lots of time debating the finer points of what should or should not be done. Nevertheless, ethics have formed the backbone of our professional status and continue to mark us out, even in a world in transition, as people to trust.

The recent question over whether or not refugees to the UK should have radiographs taken in order to assess their age provided an excellent, if unusual, example of where ethics, research and clinical dentistry overlap. To the lay person the use of radiographs to estimate someone's age seems as if it might be a very useful measure and unequivocally black and white; clear cut, unbiased compared potentially with the 'word' of the individual involved who clearly has a vested interest. While the visual rendering is literally black and white, the technique does not provide that enviable degree of certainty, in fact it is not a very accurate method as witnessed by published material in this Journal. ${ }^{1,2}$ A huge furore was unleashed when a Member of Parliament suggested the test be applied to young refugees in order to differentiate those over the age at which entry to the UK was triggered.

However, unlike the maturation status of third molars (the biological chronology in question), the ethics were and are quite clear, patients should not be subject to radiation which is not of clinically diagnostic value to their wellbeing. The BDA announced, stressed through our spokespeople and reiterated this position many times in the course of the few days that the story had media traction and, thankfully, this was also the stance taken by the UK government. The matter was closed.

The fascinating aspect about ethics though is that one can turn them around for further scrutiny and for the purposes of wider debate. So, what would the situation be if the technique was precise, or at least accurate enough to establish the chronological age of an individual beyond reasonable doubt? Would we still hold that this would be exposure to radiation for purposes that had no bearing on the person's wellbeing? Strictly speaking yes, but what if the refugee, the person desperately in need of food, shelter, safety and arguably social and medical care could be granted all that in the UK if they could be found to be within the age limit to be entitled to child entry? Could it be argued that this greater potential benefit to the child far outweighed the risk associated with a small radiation exposure to the jaws?

If this were the case, another level of ethics presents itself. One would correctly need to explain the risks and benefits to the young person in order to gain consent my own making from the UK as my country of birth to another territory where I didn't speak the language? If someone had asked (through an interpreter) if, whether in order to establish how old I was and whether or not I could remain in that place, they would like to take an X-ray of my teeth, I wonder if I would have declined? Even if they explained further that there might be a minute risk that such an X-ray may possibly, in the distant future increase my chances of suffering cancerous change, I suspect I might still have agreed; providing of course that I knew I was below the stipulated cut-off age.

I pose these questions not because this extension of the situation is an actual problem - I stress again that this is not an accurate method - but because it does provide an example of how we as professionals are faced with dilemmas which are

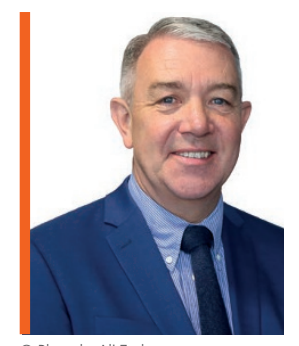

\section{'Ethics have formed the} backbone of our professional status...'

to the procedure. How to do this to a likely frightened and bewildered adolescent quite possibly separated from parents and family members and in a foreign country and when they may not speak English, let alone be able to comprehend the finer points of the risk of stochastic radiation and cell mutation? Oh, and if they do turn out to be categorised as a child, can they consent anyway? Would this be a case of a professional person being permitted to make a decision based on the patient's best interests? In thinking of the complexities of the matter I wonder what I would do, or would have done at an equivalent age, if having had to flee for no reason of rooted in culture, law and society outside our familiar world of clinical decision-making. They require of us a greater sense of our responsibilities and position in society and an enhanced need to be able to make judgments above and beyond our normal confines. In an uncertain world we must be sure that our valued and valuable professional integrity is engendered by the ethics on which it is based.

1. Aynsley-Green A. Unethical age assessment. Br Dent J 2009; 206: 337

2. Liversidge $\mathrm{H} \mathrm{M}$, Marsden P H. Estimating age and the likelihood of having attained 18 years of age using mandibular third molars. Br Dent J 2010; 209: E13

DOI: $10.1038 /$ sj.bdj.2017.1 